\title{
Insights, Ideas and Strategies on how the Fourth Industrial Revolution Technologies could enhance Competitiveness in the Global Economy
}

\author{
Akinleye Okedola \\ Akinyele \\ Lagos State Polytechnic \\ Lagos, Nigeria
}

\author{
Adegbola Jamiu \\ Sarumi \\ Lagos State Polytechnic \\ Lagos, Nigeria
}

\author{
Olawole Olakunle \\ Green \\ Lagos State Polytechnic \\ Lagos, Nigeria
}

\author{
Badmus Abdulsamad \\ University of Lagos \\ Lagos, Nigeria
}

\begin{abstract}
Nigeria ranked $124^{\text {th }}$ position in the World Economic Forum global competitiveness index $2016-2017$ and also $119^{\text {th }}$ in global innovation index 2017. The reasons for low economic figures were due to inadequate infrastructure, low technological readiness and not well-educated workforce. Moreover, high taxes, corruption, economic instability and inefficient regulations on labour and businesses are equally some of these problems. This unfavorable business environment is a huge disadvantage to most enterprises in Nigeria. They could not meet up with the current global trend of technological disruption which gives the world the capacity to connect billions of people on digital networks and potentially improve the efficiency of these organizations.

This study used empirical research method to conduct survey on manufacturers, small and medium scale business enterprises in Nigeria. The results obtained showed that enterprises that have online presence on e-commerce websites and equally adopted cashless policy of e-banking has improved customer base and higher revenue growth rate. The findings equally revealed that the implementation of new business models of Industry 4.0 and advance technologies of Industry 3.0 by entrepreneurs could make positive impact on businesses by offering new opportunities for increase productivity and driving fresh growth.
\end{abstract}

\section{Keywords}

Fourth industrial revolution, new business models, growth, increased productivity.

\section{INTRODUCTION}

Industrial revolutions are times in human history that brought about drastic shift in the social-economic life of the people driven by technological innovations. Textile manufacturing and mechanized steam locomotion were powered for energized production using powers generated by steam and water respectively in the First Industrial Revolution. While in the second, mass production in Industries was achieved with electrical energy. Industrial production was also automated using information technology and the power of electronics during the third revolution in industry. It is so obvious now that the Fourth Industrial Revolution is a derivative of the Third, since the middle of twentieth century, digital systems has been evolving. It is made up of cyber-physical systems which has joined together different technologies between the spheres of digital, biological and physical systems. There are quite a number of factors why today transformation surpass the third industrial revolution. The evolution rate of this revolution has made it possible for it to have made significant impact in a record time. Even when compared with the past industrial revolution, the speed of the big idea implementation and breakthroughs is unprecedented. The technological disruption is cutting across every facet of life and industry in the world. Lastly, the emergence of the new technologies would transform the existing systems in governance, management and production [1]

Table 1: Industrial Revolutions
\begin{tabular}{l|l} 
Industrial Revolutions & \multicolumn{1}{l}{ Period } \\
\hline First & $1760-1980$ \\
\hline Second & $19^{\text {th }}-20^{\text {th }}$ Century \\
\hline Third & Early 80 's and 90's \\
\hline Fourth & Ongoing
\end{tabular}

Fourth Industrial Revolution contained the new developments in the internet of things, automation, cloud computing technologies, robotics, artificial intelligence, autonomous vehicles, 3D Printing, nanotechnology and biotechnology among others.

Nanotechnology: It deals with the science and technology of minute objects that provides ample opportunities to the design and development of structures, materials and improved devices. It is specifically building based on small dimensions and tolerance of less than 100 nanometers used during the manipulation of molecules and atoms individually.

Robotics: It simply involves processing information, control and sensory feedback used during the design, development and operation of robotic systems.

Artificial Intelligence: This branch of engineering technology simulates natural human intelligence through design and development of intelligent machine systems. The common examples of those features are speech recognition, pattern recognition, learning and problem-solving skills.

Autonomous Vehicles: This is an emerging technology in automobile (self-driving car) and also self-driving bicycle powered by Google. The system actually uses technologies like GPS, laser light, radar to detect their environments for easy navigation.

Biotechnology: It involves the use of living things to develop and make technological products. It encompasses any technological solutions that uses biological systems, living organism, or its derivatives.

Automation: It refers to an automatic control with reduced human intervention. It actually helps to control several machines such as an aircraft, fire detection system, firefighting systems, boilers, factories processes and so on. 
The key objective of this research is to investigate how Industry 3.0 and Industry 4.0 technological solutions could drive fresh growth and productivity in businesses in Nigeria. We investigate how this could be achieved in an environment with inadequate infrastructure, low technological readiness and unstable government policies. This study is significant in many ways. Primarily it identifies the key factors driving success rate in businesses in Nigeria. It showed how the adoption of 4IR and Industry 3.0 technologies of smart factory, e-commerce, e-banking applications could help entrepreneur to succeed despite the harsh business environment.

\section{LITERATURE REVIEW}

History has shown times and times over that the first industrial revolution that existed between eighteenth and ninth century was at the time when humans were majorly agrarian and rural society in both America and Europe first become urban and industrialized.

Prior to the time when industry became revolutionized, people manufacture products in their homes with hand tools and ordinary machines.

The first industrial revolution became a significant turning point in manufacturing. There was a paradigm shift which gave birth to highly powered factories and special purpose machine which enable mass production.

The discovery of steam engine brought about great transformation in driving machines in iron factories and textile industries. Likewise, transportation systems like the railways, vehicles, ships and steam boats were easily propelled. Steam turbines also helped in generating electricity.

The era of the first industrialization came with multiple solutions to humanity problems. First, there was mass production of manufactured products, secondly, it brought about mass employment for the people and improved living standards. [2]

During the time people were making textiles at home, merchants usually supply the raw materials alongside ordinary equipment and later come to pick up finished goods. There was a little challenge as of the time because worker now come up with their work schedules which does not go down well with merchants and eventually led to low efficiency.

Around the beginning of 1700 s, several innovative technologies led to increased productivity which reduced human energy considerably.

The textile industry had significant improvement. It started with invention of the spinning machine called 'jenny' around 1764 by an Englishman James Hargreaves. The machine enables the user to generate spools of thread in multiples simultaneously. Around the time the inventor died, there were over twenty thousand spinning machines being used all around Great Britain. Samuel Compton who lived around 1753-1827, another great inventor, also improved upon the design of this machine. Lastly, power loom was discovered by Edmund Cartwright. This equipment simplified the process of weaving cloth through mechanization.

The industrial revolution also gave a boost to the development of iron and steel industry. Around the beginning of $18^{\text {th }}$ century, an easier and cheaper method to transform iron ore into cast iron with a coke-fueled furnace was discovered by another Englishman Darby Abraham.
The revolution in industry continued with the new discovery of a system for mass production of steel. Thereafter, steel and iron became very valuable materials commonly used to design machines, tools, ships and reinforced concrete in building structures.

The transportation systems were well transformed during the first industrial revolution with the discovery of steam engine. Previously, finished products, raw materials were hauled and human were transported via carts (horse-drawn carriage) and boats through rivers and canals.

It started in the early $19^{\text {th }}$ Century when the first steamboat was built successfully for commercial purposes by an American Engineer called Robert Fulton. Later, steamships were designed moved freight across the Atlantic Ocean. Thereafter, steam locomotive railway system was constructed by a British engineer called Trevithick Richard.

Road design and construction technique was equally improved by a Scottish Engineer McAdam John. This helped building a less muddy, smoother and everlasting roads.

\section{THEORETICAL DEVELOPMENT}

Most small and medium scale enterprises and big factories face enormous challenges in breaking through due to the harsh business environment in Nigeria and also due to inability to adopt the new technologies of Fourth Industrial Revolution(4IR) business models in line with global best practices and stay competitive. This study researched the impact of 4IR and Industry 3.0 on sales, productivity and growth of businesses and how they could thrive despite the level of infrastructural development, funding challenges, and technological readiness.

\subsection{INDUSTRY 4.0}

Industry 4.0 is a newly coined nomenclature for the Fourth Industrial Revolution which the represent the new trend in automatic control systems for manufacturing technologies and Big Data. It is the basis of the smart factory. It spans across different areas like cloud computing, cognitive computing, and internet of things.

Cyber-physical systems basically generate the virtual form of the physical world to make a non -central decisions within the well structure smart factories. The internet of things creates a platform whereby cyber-physical systems inter communicate in real time with humans online by offering both internal and external organizational services. [4]

There are basically four areas of principles of design that help companies in the identification and implementation of the fourth industrial revolution.

Technical Assistance: This technical support is provided by cyber physical system to assist humanity when they take up the challenge of a dangerous, unpleasant, and exhaustive task.

Information transparency: This is similar to virtual reality whereby digital plant designs are enriched with aggregated sensor data by creating the virtual copy of the physical world

Decentralized Decisions: This is the functionality of cyberphysical systems to make some independent decisions when performing an autonomous task

Interoperability: It is a feature of an artificial intelligence whereby machines, sensors and people easily communicate and connect together using the internet of things technology 


\subsection{Internet of Things [IOT] and Industry Technology}

The working principle of IOT started with a transformation of the world we live in today. It cuts across every facet of our lives, from the way we commute, to the way we get medical attention and how we use energy in our homes and work places.

Engineers are now embedding special chips and sensors to the physical things that surround us in order to communicate with us easily and improve its functionalities to serve us better. Each of them transmitting and receiving data from a centralized database.

Valuable information like real-time city road traffic situation report, where residents of a city can park their vehicles, real time diagnosis of an automobiles and monitoring of our health condition. All these features were put together by the internet of things when different information come together to provide common language for both software and hardware systems to work together.

It starts with the physical device first establishing a secure connection with the internet of things platform. This same platform then integrates the data together with other surrounding devices and then immediately shares the most valuable processed data with applications by applying analytics technique to achieve some specific needs in the industries.

For example, you went to bed with a health monitoring band in your hand and as you are sleeping in your room, suddenly in the middle of the night, you develop a high blood pressure which puts you in grave danger of heart attack if you fail to get medical attention in good time, the band in your hand immediately establish a communication link the internet of things platform. The platform instantly alerts the nearest Emergency Medical Service (EMS) with the information of your GPS location and your house address. The EMS response team arrived at your residential apartment to rescue you. [5] [6]

\subsection{Advance Technological Solutions of Industry 3.0 for Business Enterprise}

Vconnect: It is a website that help business owners who subscribed to their services to have a web presence by uploading their business address and contact information on their site. They also provide their subscribers with articles that could make their business better. Comprehensive business news, funding sources news, invaluable insights about running a successful business. All these in one quick and concise package.

Google Map: Google Map could help business enterprises to be more productive in many ways. It is an extremely good marketing tool from small to medium scale business. It is a great weapon to help people know where these businesses are located and to tell that at a specific area, there is a business that can offer a specific products or services. There exist three main reasons why business owners should add their businesses to google map. The first, by having a business listed on google map, owners can actually offer a google map direction to people who wish to visit their office or store and do not exactly know how to reach them. Secondly, with a business registered on google map it can as well be listed on Google places service which is an online business directory that help businesses to show up on search results when people look for product or service the particular organization provide.
Thirdly, by listing a business on google map, it means it is getting an exclusive online presence and people (prospects, consumers, businesses) will get to know about it.

P.O.S Terminals: It is called Point of Sale Terminal. There are several reasons for a business to use a POS rather than traditional cash register. It offers better customer service, which may ultimately grant your company a more loyal customer base. This is because it is secured, saves time and easy to operate. It provides users unlimited access to different customized reports. These reports carry valuable insights on inflow and outflow of cash and a better understanding of the progress of the business. More so, advance reporting functions shows sales trends and variation in product demand while helping merchants to properly order for future stocks where necessary to meet the demands of their customers. It also has feature that monitors each employee transaction records. This will provide the merchant the opportunity to easily call to account any erring employee that might jeopardize the business interest through fraudulent activities.

Mobile Money: It is a service whereby customers use their mobile phone device to receive and send monetary values or more simply put, to transfer money electronically from one person to another using a mobile phone as Mobile Wallet. It is also a real tool for economic growth and development if fully explored.

\section{METHODOLOGY}

The current research was conducted using empirical research method to evaluate Industry 3.0 and Fourth Industrial Revolution technologies impact on business enterprises in Lagos, Nigeria. We want to investigate the improvement in sales, productivity and growth, the general awareness and issue with non-adoption.

The survey was done to examine the respondents feedback. We used questionnaires to investigate 50 businesses in Lagos, Nigeria based on the following categories.

\section{Category A:}

The respondents in category A were majorly manufacturing industries and the questions they were asked was why they were still stock with industry 2.0 and 3.0 world and not the smart factory concept 4.0 .

\section{Category B:}

The respondents in category B were small and medium scales businesses and the questions they were asked about their level of awareness, adoption and impact of e-commerce technology and the reasons why many of them do not adopt the cashless policy of e-banking. The survey specifically checked the online presence of these businesses on the e-commerce websites (konga, Jumia, OLX and Vconnect) in Nigeria.

\section{RESULTS}

Table 2: Respondent statistics survey result

\begin{tabular}{|l|l|}
\hline No of Respondents & 50 \\
\hline Adoption of e-commerce & $33 \%$ \\
\hline Non- Adoption of e-commerce & $76 \%$ \\
\hline $\begin{array}{l}\text { Adoption of e-banking (P.O.S } \\
\text { terminal) }\end{array}$ & $22 \%$ \\
\hline $\begin{array}{l}\text { Non-adoption of e-banking (P.O.S } \\
\text { terminal) }\end{array}$ & $78 \%$ \\
\hline $\begin{array}{l}\text { Level of awareness of 4IR smart } \\
\text { factory }\end{array}$ & $10 \%$ \\
\hline
\end{tabular}




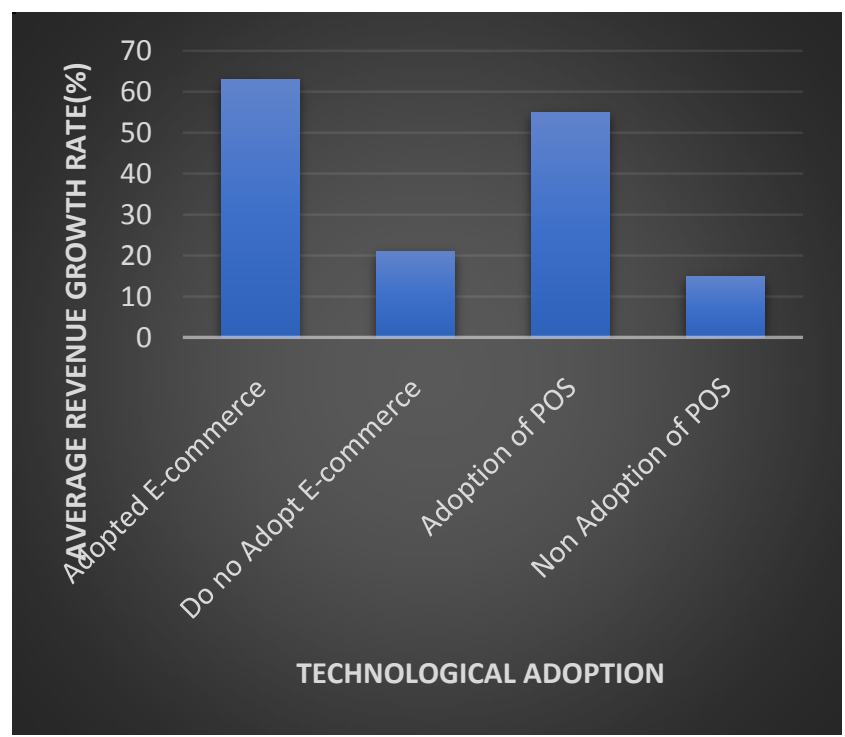

Figure 1: Graph showing Average Revenue Growth rate against Technological Adoption of E-commerce

Table 3: Showing various Technologies Adopted versus Average Revenue Growth Rate

\begin{tabular}{|l|l|}
\hline Business & $\begin{array}{l}\text { Average Revenue Growth } \\
\text { Rate }\end{array}$ \\
\hline Adopted e-commerce & $63 \%$ \\
\hline Do not adopt E-commerce & $21 \%$ \\
\hline $\begin{array}{l}\text { Adopted E-banking service } \\
\text { (P.O.S Terminal) }\end{array}$ & $55 \%$ \\
\hline $\begin{array}{l}\text { Do not adopt E-banking } \\
\text { Service (P.O.S Terminal) }\end{array}$ & $15 \%$ \\
\hline
\end{tabular}

Revenue Growth Rate =

Total revenue last year - Total revenue current year Total revenue last year

The online survey using Google docs was conducted. The URL link was sent by e-mail and via Instant Messenger to 50 business owners in Lagos Nigeria. This is the southwest geopolitical zone in Nigeria.

Table 4: Demographic Characteristics of Respondents

\begin{tabular}{|l|l|l|l|}
\hline Attributes & & Frequency & Percentage \\
\hline Gender & Male & 35 & $70 \%$ \\
\cline { 2 - 4 } & Female & 15 & $30 \%$ \\
\hline \multirow{4}{*}{ Age } & $20-29$ & 12 & $24 \%$ \\
\cline { 2 - 4 } & $30-39$ & 29 & $58 \%$ \\
\cline { 2 - 4 } & Over 40 & 9 & $18 \%$ \\
\hline \multirow{3}{*}{ Business } & Small Scale & 13 & $26 \%$ \\
\cline { 2 - 4 } & Medium Scale & 27 & $45 \%$ \\
\cline { 2 - 4 } & Manufacturers & 10 & $16.7 \%$ \\
\hline
\end{tabular}

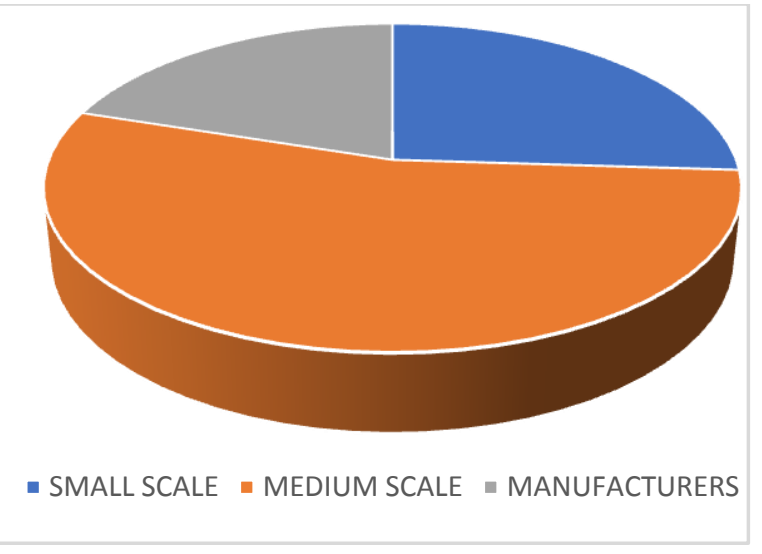

Figure 2: A pie chart showing respondent frequency of different businesses considered in the case study

\section{DISCUSSION OF RESULTS}

As presented in Table 2, out of 50 businesses researched, the respondents that adopted e-commerce technology were just $33 \%$. $77 \%$ of the respondents do not adopt e-commerce technology for their products. Their reason was majorly due low level of awareness and poor computer literacy level. However, the respondents who utilized P.O.S terminals were just $22 \%$ while others that do not adopt it were $78 \%$. They complained about security concerns of online transaction, bank charges and lack of awareness.

Table 3 results showed that the annual revenue growth rate of companies that adopted e-commerce and P.O.S terminal technologies were $63 \%$ and $55 \%$ respectively. While those that do not utilize e-commerce and P.O.S terminal technologies were $21 \%$ and $15 \%$ respectively.

The results above in Table I and Table II has proved beyond reasonable doubt that both Industry 3.0 and 4IR technological solutions are effective tools in driving growth and increasing productivity in business enterprises in Nigeria. The government has to improve on infrastructural development, increase awareness on the modern technological adoption and also provide research and development funds for innovative companies. Business owners and manufacturers should train their employees for the next wave of technological disruption as it would adversely affect the existing unskilled workforce. If these above suggestions were backed up with concrete action by the Nigerian Government and business owners, it would go a long way in boosting the Nigeria Economy.

\section{CONCLUSION}

This study has provided some data on the percentage of business enterprise owners who implemented the e-commerce technology and cashless policy of e-banking in Nigeria. It equally investigates the impact Industry 4.0 will make and the growing skill-gap of the existing workforce. Empirical research method was implemented to conduct our survey on manufacturers, small and medium scale enterprises and the results obtained showed that the annual revenue growth rate and customer base of companies that adopted new business models of Industry 3.0 and 4.0 far surpassed others who do not adopt it. It is also recommended for future research work to focus more energy on developing affordable, reliable and easy to use technology that would digitize business models in the third world economy. 


\section{REFERENCES}

[1] Harsha Vardhan, Geospatial World, "The fourth Industrial Revolution- A genesis", [June 14, 2017]. Available: https://www.geospatialworld.net/blogs/fourth-industrialrevolution-genesis/. [Accessed: June 19, 2017]

[2] The History Channel, A\& E Network Publisher, "Industrial Revolution", [2009]. Available: http://www.history.com/topics/industrial-revolution. [ Accessed: September 23, 2017]

[3] Wikipedia, The free Encyclopedia, “ Industrial Revolution", [Available: September 21, 2017], https://en.wikipedia.org/wiki/Industrial_Revolution, [Accessed: September 19, 2017].

[4] Wikipedia the free Encyclopedia, "Industry 4.0", [ Available: $\quad$ September $22, \quad 2017]$ https://en.wikipedia.org/wiki/Industry_4.0. [Accessed: September 23, 2017]

[5] Margret Rouse, Tech Target, "Internet of Things Agenda", [Available: January, 2017], http://internetofthingsagenda.techtarget.com/definition/In ternet-of-Things-IoT. [Accessed: September 22, 2017]

[6] Wikipedia the free Encyclopedia, "Internet of Things", [Available: September 19, 2017], https://en.wikipedia.org/wiki/Internet_of_things [Accessed: September 19, 2017]

[7] Ericson, "A study of the Adoption of Internet of things among Danish Companies" [Available: March 28, 2017], https://en.wikipedia.org/wiki/Internet_of_things. [Accessed: September 23, 2017]

[8] Gary Coleman, World Economic Forum," Companies benefits from fourth Industrial Revolution but do countries?", [June 21, 2017]. Available: https://www.weforum.org/agenda/2017/06/fourthindustrial-revolution-country-competitiveness/[Accessed: September 23, 2017]

[9] The Global Innovation Index 2017 Report, [September 20, 2017]. Available: https://www.globalinnovationindex.org/. [Accessed: September 23, 2017]
[10] E-Commerce Milo, 7 "Reasons why traditional retailers would fail in e-commerce", [Jan. 13, 2016 ], retrieved 10th Nov. 2016 from http://www.ecommercemilo.com/2016/01/7-reasonswhy-traditional-retailers-fail-ecommerce.html.

[11] Bradford, Alina. (March 24, 2015) Empirical evidence: a definition, retrieved on 12th Nov. 2016, from http://www.livescience.com/21456-empirical-evidencea-definition.html

[12] Cagaoan, Angelo K. A, Buenaobra, Anne. M. J. V., Martin, Trina. A. M, Paurillo and Jonathan, "Privacy awareness in E-Commerce", International Journal of Education and Research, Vol. 2 No. 1 January 2014.

[13] E-Commerce Milo, (Nov. 18, 2015) Analysis on top 10 online shopping sites in Malaysia, retrieved 10th Nov. 2016 from http://www.ecommercemilo.com/2015/11/analysis-top10-online-shopping-sites-malaysia.html.

[14] Ponte, E. B., Carvajal-Trujillo, E., and EscobarRodríguez, T. 2015. Influence of trust and perceived value on the intention to purchase travel online: Integrating the effects of assurance on trust antecedents. Tourism Management, 47, 286-302.

[15] Chiejina, C. 2014. Investigating the Significance of the 'Pay on Delivery' Option in the Emerging Prosperity of the Nigerian e-commerce sector. Journal of Marketing and Management, 5, 1, 120-135.

[16] Nepomuceno, M. V., Laroche, M. and Richard, M. 2014. How to reduce perceived risk when buying online: The interactions between intangibility, product knowledge, brand familiarity, privacy and security concerns. Journal of Retailing and Consumer Services, 21, 619-629.

[17] The Manufacturer, "Industry 4.0, why some manufacturers are still stuck in a 2.0 and 3.0 world?" [Available: August 30, 2017]. Available: https://www.themanufacturer.com/articles/industry-4-0many-manufacturers-are-still-stuck-in-a-2-0-and-3-0world/ [Accessed: September 20, 2017] 